\title{
A Study of the Outcomes of Endovenous Laser Therapy in the Treatment of Varicose Veins
}

\author{
Bhaskar Musande, Manohar Kalbande, Tanvi Tolat
}

\begin{abstract}
Background: Lower limb varicose veins affect 25 million people in worldwide, with complaints varying from purely cosmetic to debilitating disease, all of which require some sort of intervention. Methodology: 50 patients of varicose veins admitted under Department of Surgery in MGM Medical College and Hospital, Aurangabad, from April 2014 to November 2015, were studied. All the patients underwent Endovenous Laser Therapy[ EVLT] under local anaesthesia under ultrasonography guidance using 980nm diode laser. Foam Sclerotherapy was given in case of any residual varicosities in the same sitting. Patients were followed up after 1week, 1 month, 3 months and 6 months and regression of symptoms alongwith occurrence of any complications were noted. Results: Most of the patients (58\%) complained of mild pain 1 week after the procedure, $34 \%$ had no pain while $4 \%$ had moderate pain. Dilated veins and bleeding disappeared immediately after EVLT. While edema, eczema, ulcers and itching disappeared with time. Pigmentation was still present in some patients at 6 months, but its intensity had significantly faded with time. $62 \%$ of the patients complained of pain , 16\% patients had ecchymosis, $10 \%$ patients had paraesthesia and $2 \%$ patients had a palpable superficial vein thrombus one week after the procedure, which disappeared before the $2^{\text {nd }}$ follow-up visit (before 1 month). Only $4 \%$ of our patients returned with recurrence. Conclusion: The results of EVLT are comparable to the results of conventional surgery or other minimally invasive methods for the treatment of varicose veins.
\end{abstract}

Keywords: varicose veins, endovenous laser therapy, foam sclerotherapy, minimally invasive , chronic venous insufficiency

\section{Introduction}

Lower limb varicose veins are the commonest of all vascular disorders. It is one of the important vascular conditions that affect 25 million people in western civilizations. ${ }^{1}$

Most of these persons have either symptoms or complications from chronic venous in sufficiency and a substantial number suffer economic hardship from the resulting disability.

Considerable advances in understanding of pathophysiology of venous disease and modern imaging techniques, in particular colour duplex ultrasonography, have revolutionized the concept of management of varicose veins.

The definitive operative treatment when indicated is well established depending upon the type of varicosities. The operatives' treatment is always proceeded and followed by conservative treatment. The conservative measures may be the only treatment when the operative interference is not advisable. The recurrent nature of the disease, high cost to the health care system, and the ineffectiveness of current treatment modalities for Chronic Venous

Insufficiency (CVI) underscore the need for CVI-related research. People who suffer from varicose veins often have a family history of varicose veins. This family history also increases the risk of further varicose veins developing aftersurgery. Surgery for recurrence is associated with more complications because;scarring from the previous operation can make the surgery more difficult,operation can take longer and there are increased risks to develop a wound infection, seroma formation and rarely permanent lymphoedema of the leg. For these reasons it might be worth considering other therapies like foam Sclerotherapy, Radiofrequency Ablation(RFA), and Endovenous Laser Therapy(EVLT).
Thus we have made an earnest endeavour to study the various outcomes of endovenous laser therapy in the treatment of varicoseveins.

\section{Methodology}

\section{Study Design}

A prospective follow up study was undertaken in the Department of Surgery, MGM Medical College and Hospital, Aurangabad from April 2014 to November 2015.A total of 50 patients of varicose veins of the lower limbs and its associated symptoms were studied.

\section{Inclusion Criteria}

- Age between 18 and 70 years, either sex, elective admission

- Symptomatic GSV reflux (primary or recurrent) confirmed by duplex imaging.

- Varicose veins without GSV incompetence on duplex imaging

- Associated small saphenous vein reflux and deep venous incompetence on duplex imaging

- Isolated multiple perforator incompetence

- Residual perforator

- Recurrent perforator

- Patients who are under high risk for regional or general anaesthesia.

- Previous history of endovenous laser therapy\& foam sclerotherapy.

Exclusion criteria

- Deep Vein Thrombosis.

- Clot in great saphenous vein.

- Peripheral vascular disease.

- Pregnancy. 


\section{International Journal of Science and Research (IJSR) \\ ISSN (Online): 2319-7064 \\ Index Copernicus Value (2013): 6.14 | Impact Factor (2014): 5.611}

\section{Procedure}

Patients were seen on OPD basis, history was taken, symptoms and signs recorded followed by general and local examination. All patients were admitted and subjected to colour venous doppler of the diseased limb.Patients who presented with bilateral varicose veins were treated for the limb with more severe complaints. All the patients underwent Endovenous Laser Therapy under local anaesthesia under ultrasonography guidance using 980nm diode laser.

Inj.Ceftriaxone was given as prophylactic antibiotic and Inj.Diclofenac used as analgesic with aseptic precaution, the affected vein is cannulated above the knee using 23guage spinal needle and a guide wire and a sheath is passed over the guide wire Tumescent anaesthesia $(30 \mathrm{ml} 2 \%$ Inj.Lidocaine, $10 \mathrm{ml}$ Inj.Sodium bicarbonate, $10 \mathrm{ml}$ Inj.Bupivacaine and 300 сc normal saline). is infiltrated along the vein. Laser fibre is inserted up to the tip of the catheter and fired

while withdrawing.

The patients were then asked to stand. Foam Sclerotherapy was given in case of any residual varicosities in the same sitting.

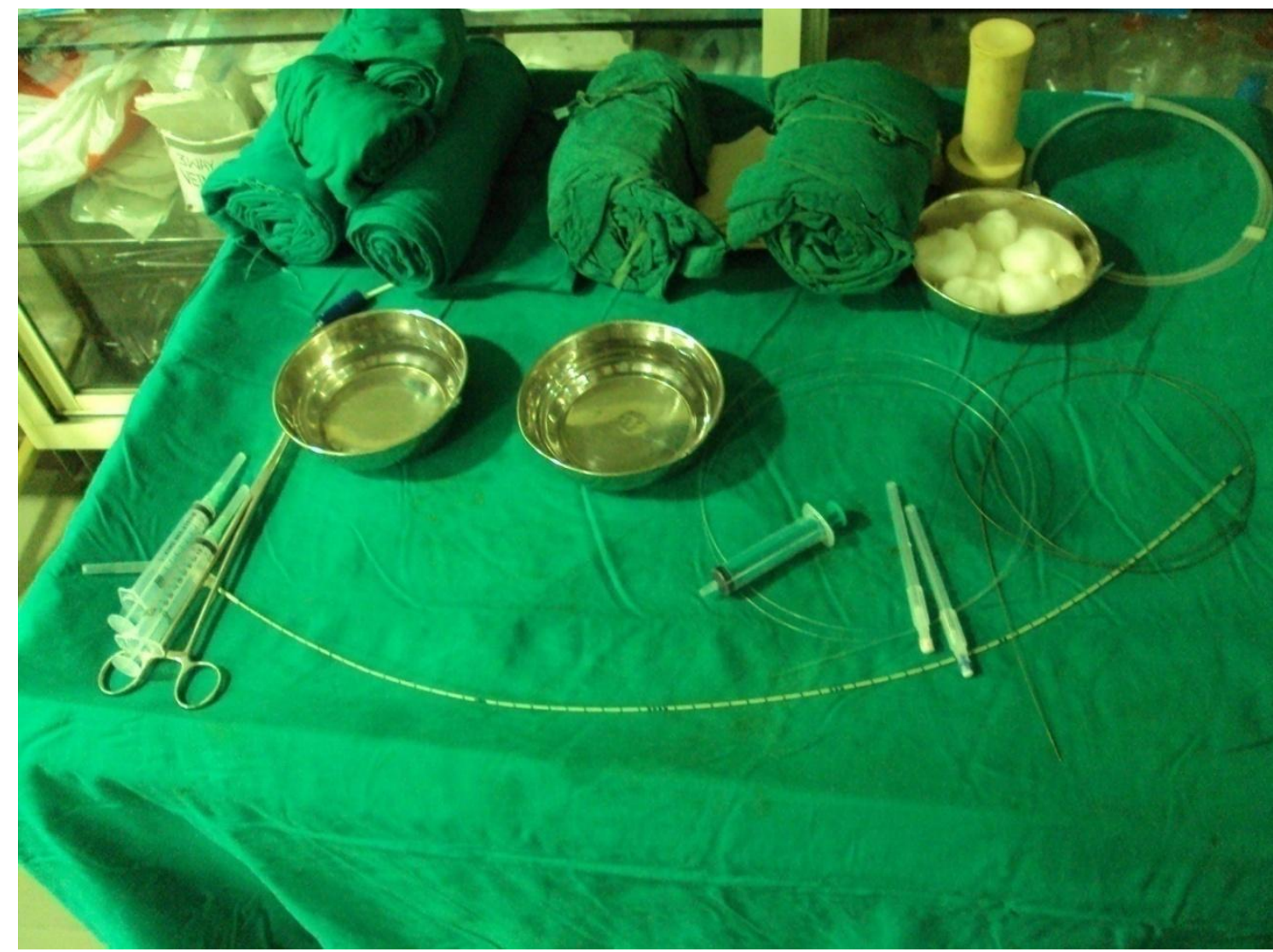

Photo 1: Materials used-Tumescent anaesthesia,23 guage spinal needle, J-tip guidewire, sheath, luer lock syringe.

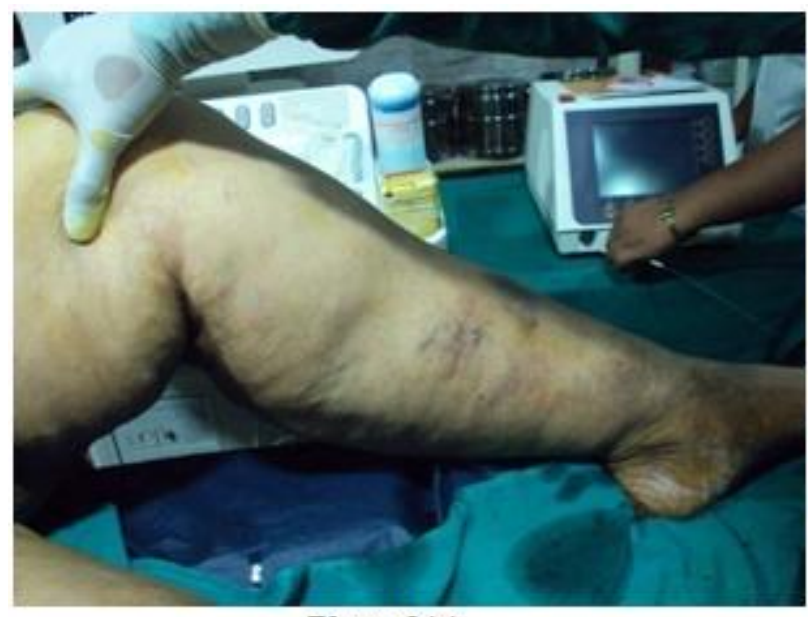

Photo-2(a)

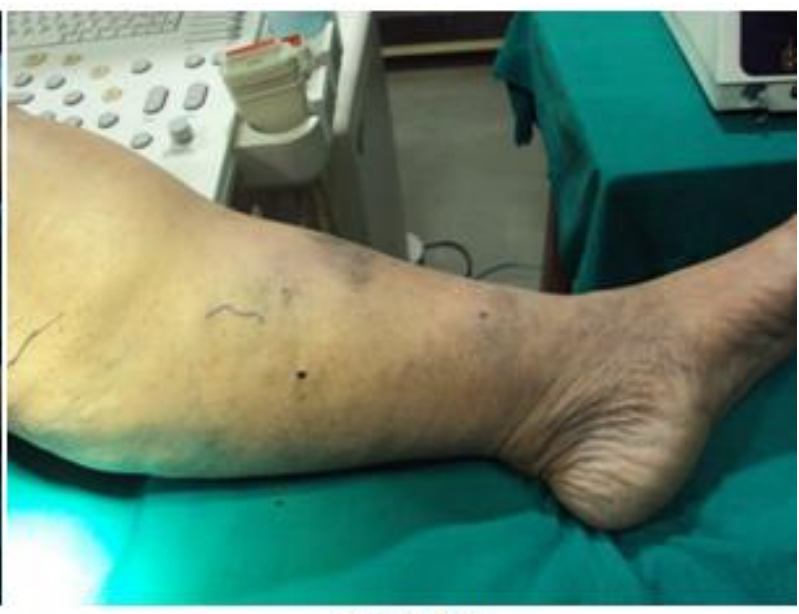

Photo-2(b)

Photo $2(\mathbf{a}, \mathbf{b})$ : Before and immediate postoperative photographs of our patient who underwent EVLT with patient still on OT table. 


\section{International Journal of Science and Research (IJSR) \\ ISSN (Online): 2319-7064}

Index Copernicus Value (2013): 6.14 | Impact Factor (2014): 5.611

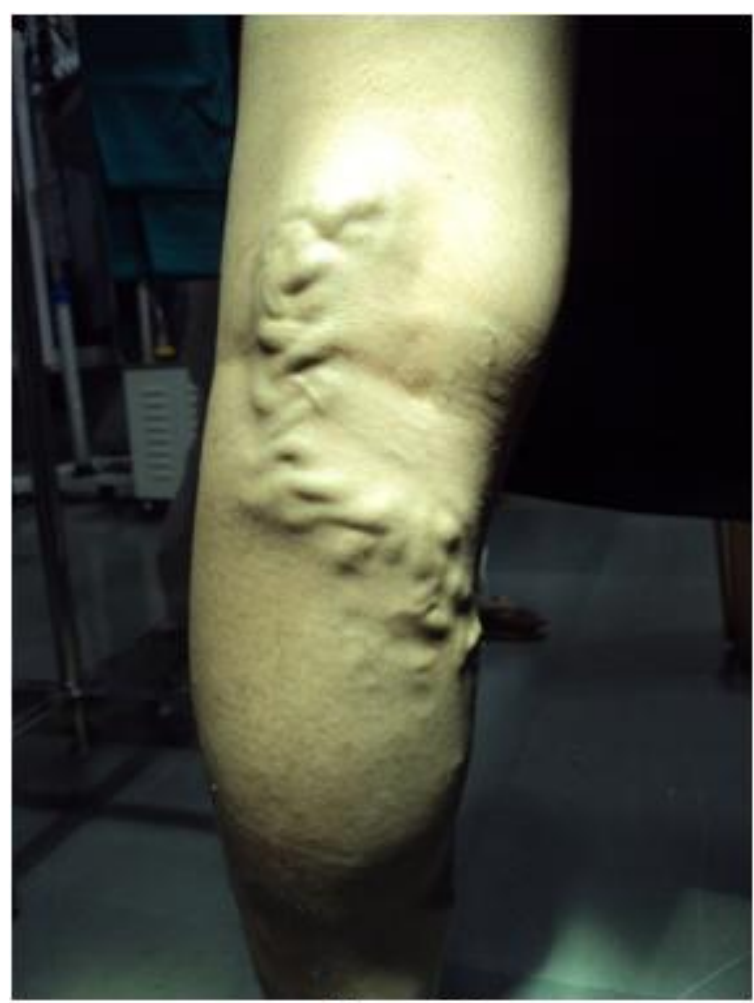

Photo-3(a)

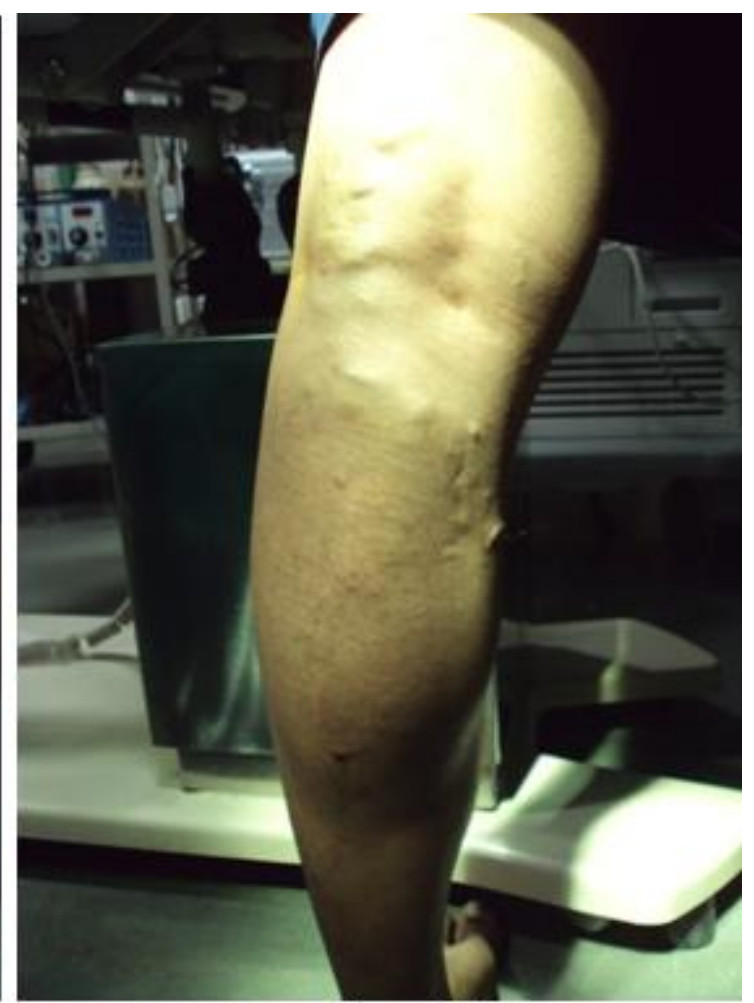

Photo-3(b)

Photo-3 (a,b): Prior to EVLT and immediate postoperative picture of patient of varicose veins..

The patients were given stockings to wear post operatively and discharged. Follow up was done 1 week postoperatively, after 1 month, 3months and 6 months when regression of symptoms and occurrence of complications (pain, ecchymosis, paraesthesia, palpable superficial thrombus)were assessed.

The outcomes of EVLT in our study were then analysed statistically using SPSS (Statistical Packages for Social Sciences version 20th) in MS Excel Sheet and then compared with historical and world literature.

\section{Results}

The present study was conducted in the Department of Surgery, MGM Medical College and Hospital, Aurangabad during the period of April 2014 to Novober 2015. A total of 50 patients of varicose veins were subjected to Endovenous Laser Therapy.

\section{Patient demographics}

$68 \%$ of the patients of varicose veins to undergo Endovenous Laser Therapy were female and 32\% were male. The mean age group of the patients of varicose veins subjected to Endovenous Laser therapy was $42.36 \pm 12.34$. $74 \%$ of the patients presented with unilateral signs and symptoms with $26 \%$ showing bilateral involvement. The more common side involved was left side (66\%) compared to right side (34\%)

$62 \%$ of the patients had normal Body Mass Index(18.5-24.9 $\mathrm{kg} / \mathrm{m} 2), 26 \%$ patients were overweight(25-29.9 kg/m2) and $12 \%$ were obese $(\geq 30 \mathrm{~kg} / \mathrm{m} 2)$.

\section{Doppler Report}

The most common vein involved was the GSV (94\%) in our study. 82\% had exclusive GSV involvement, 6\%had exclusive SSV involvement with $12 \%$ having both veins involved. In the present study 60\% patients had perforator incompetence, $86 \%$ and $14 \%$ had SFJ and SPJ incompetence respectively. $4 \%$ patients were known case of DVT while $6 \%$ were known cases of superficial vein thrombosis.

\section{Operative Parameters}

The average number of days the patients were kept admitted was2.4 \pm 0.67 . The Mean value of the length ablated was $52.3 \pm 18.63 \mathrm{~cm}$, Mean value of time taken was $230.66 \pm 82.86$ seconds, Mean value of the energy used was $5147.96 \pm$ 1780.95 Joules and Mean value of Power being $31.68 \pm 14.84$ Watts.

Table 1: Mean of EVLT Parameters

\begin{tabular}{|c|c|c|c|c|}
\hline & Minimum & Maximum & Mean & Std. Deviation \\
\hline Length(cm) & 11.00 & 95.00 & 52.30 & 18.63 \\
\hline Time(sec) & 40.00 & 375.00 & 230.66 & 82.86 \\
\hline Energy(Joule) & 850.00 & 9000.00 & 5147.96 & 1780.95 \\
\hline Power(Watt) & 12.00 & 72.00 & 31.68 & 14.84 \\
\hline
\end{tabular}

26\% of our patients required Foam Sclerotherapy for the treatment ofresidual varicosities, immediately after Endovenous Laser therapy in the same sitting.

Table 2: Patients requiring Foam Sclerotherapy after EVLT

\begin{tabular}{|c|c|c|}
\hline Foam Sclerotherapy & No. of patient & Percentage \\
\hline YES & 13 & 26.0 \\
\hline NO & 37 & 74.0 \\
\hline Total & 50 & 100 \\
\hline
\end{tabular}




\section{International Journal of Science and Research (IJSR) \\ ISSN (Online): 2319-7064}

Index Copernicus Value (2013): 6.14 | Impact Factor (2014): 5.611

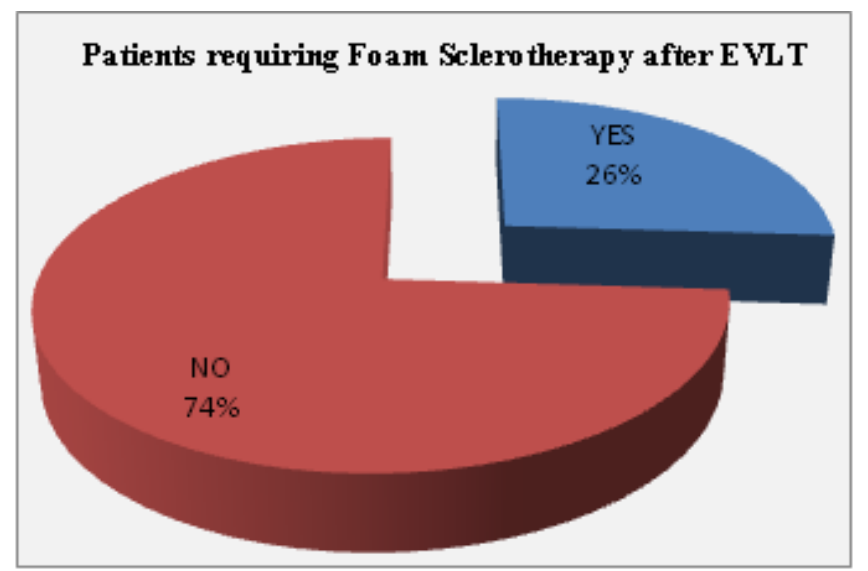

\section{Outcomes}

Most of the patients (58\%) complained of mild pain 1 week after the procedure, $34 \%$ had no pain while $4 \%$ had moderate pain.

Table 3: Pain score at follow up after 1 week:

\begin{tabular}{|c|c|c|}
\hline Pain Score & No. of Patients & Percentage \\
\hline No Pain & 17 & 34.0 \\
\hline Mild [1 to 3] & 29 & 58.0 \\
\hline Moderate [4 to 6] & 02 & 4.00 \\
\hline Severe [ 7 to 10] & 00 & 00 \\
\hline Total & 50 & 100.0 \\
\hline
\end{tabular}

Graph 1: Patients requiring Foam Sclerotherapy after EVLT

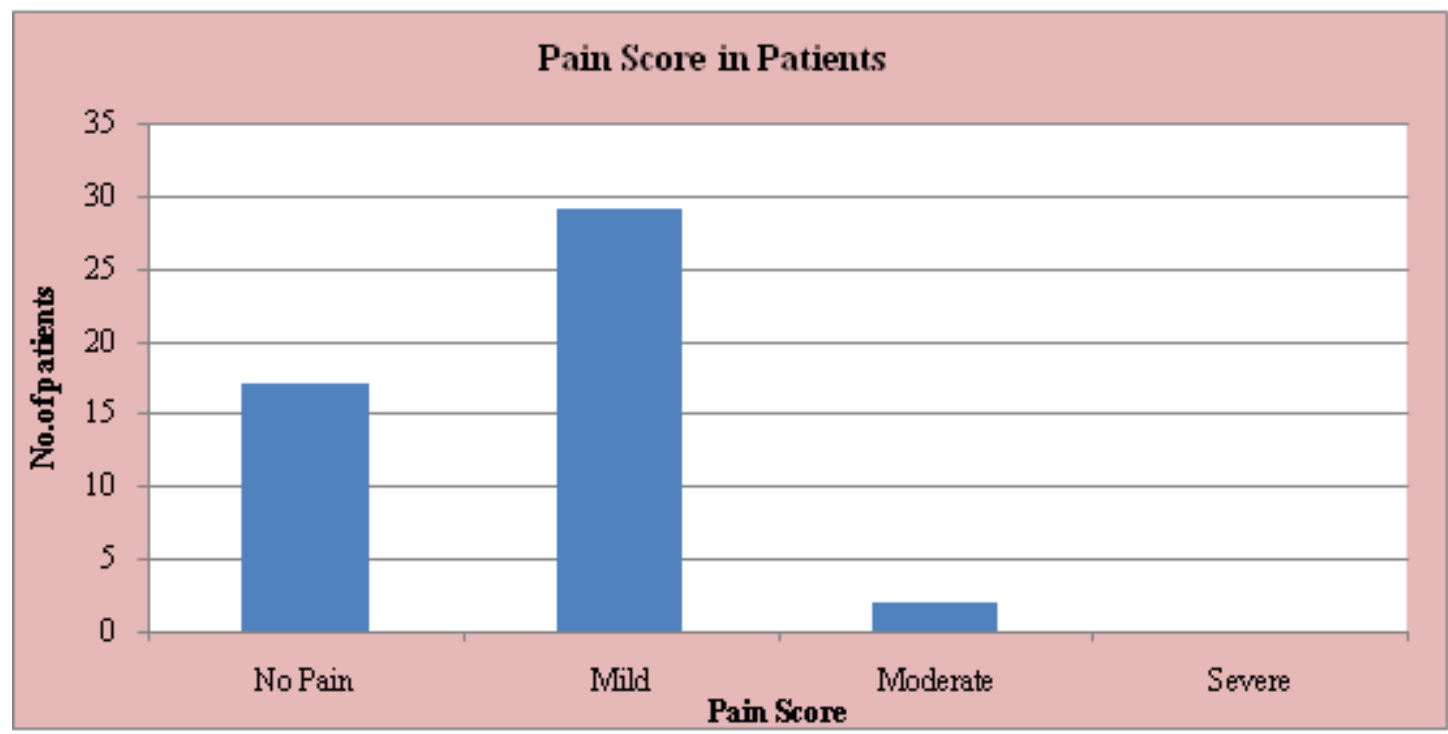

Graph 2: Pain score at follow up after 1 week

According to the statistical analysis the symptoms of dilated veins and oedema have significantly reduced within 1 week $(\mathrm{p}<0.000)$.Also itching significantly reduced after one month $(\mathrm{p}<0.05)$ and ulcers after 3 months $(\mathrm{p}<0.000)$. According to the statistical analysis, reduction in pigmentation $(\mathrm{p}=0.327)$, eczema $(\mathrm{P}=0.153)$ and bleeding $(\mathrm{P}=0.315)$ is not significant.

Table 4: Regression of Signs \& Symptoms in Patients:

\begin{tabular}{|c|c|c|c|c|c|c|c|c|c|}
\hline Symptoms & $\begin{array}{c}\text { Before } \\
\text { treatment }\end{array}$ & \begin{tabular}{|c|} 
After \\
treatment \\
1 week \\
\end{tabular} & p-value & $\begin{array}{c}\text { After } \\
\text { treatment } \\
\text { 1Month } \\
\end{array}$ & p-value & $\begin{array}{c}\text { After } \\
\text { treatment } \\
\text { 3Months }\end{array}$ & p-value & $\begin{array}{c}\text { After } \\
\text { treatment } \\
6 \text { Month } \\
\end{array}$ & P-value \\
\hline Dilated Veins & 47 & 0 & $\mathrm{P}<0.000$ & 0 & $\mathrm{P}<0.000$ & 0 & $\mathrm{P}<0.000$ & 2 & $\mathrm{P}<0.000$ \\
\hline Leg Cramps & 29 & 2 & $\mathrm{P}<0.000$ & 0 & $\mathrm{P}<0.000$ & 0 & $\mathrm{P}<0.000$ & 0 & $\mathrm{P}<0.000$ \\
\hline Itching & 05 & 8 & & 8 & & 7 & & 5 & $\mathrm{P}=1.00$ \\
\hline Pigmentation & 09 & 8 & & 0 & $\mathrm{P}<0.000$ & 0 & $\mathrm{P}<0.000$ & 0 & $\mathrm{P}<0.000$ \\
\hline Oedema & 27 & 8 & $\mathrm{P}<0.000$ & 1 & $\mathrm{P}<0.000$ & 0 & $\mathrm{P}<0.000$ & 0 & $\mathrm{P}<0.000$ \\
\hline Eczema & 01 & 2 & & 2 & & 0 & & 0 & \\
\hline Ulcer & 11 & 9 & & 7 & & 1 & $\mathrm{P}<0.000$ & 0 & $\mathrm{P}<0.000$ \\
\hline Bleeding & 01 & 0 & $\mathrm{P}<0.000$ & 0 & & 0 & & 0 & \\
\hline
\end{tabular}




\section{International Journal of Science and Research (IJSR) \\ ISSN (Online): 2319-7064}

Index Copernicus Value (2013): 6.14 | Impact Factor (2014): 5.611

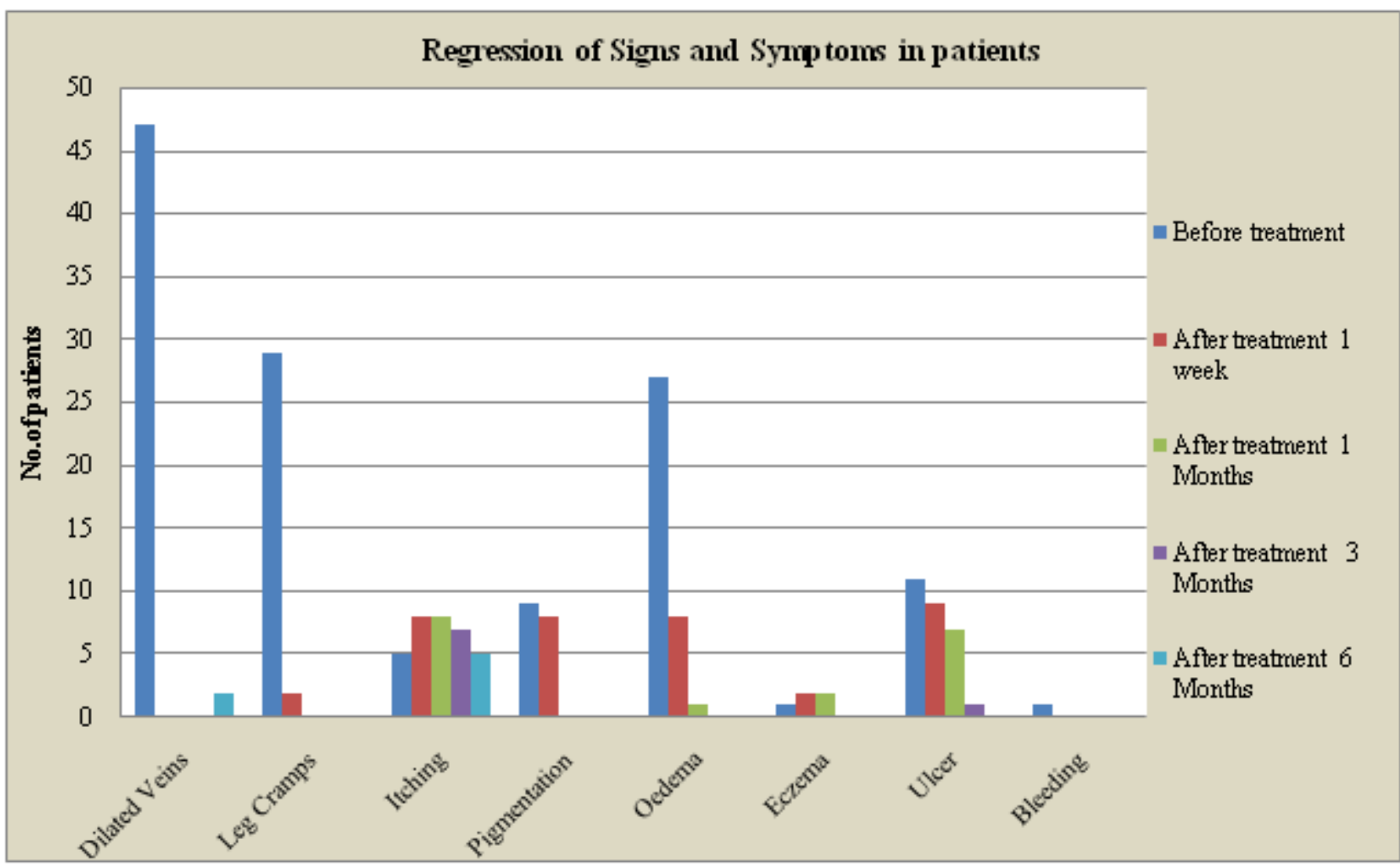

Graph 3: Regression of Signs \& Symptoms in Patients

$62 \%$ of the patients complained of pain, $16 \%$ patients had ecchymosis, $10 \%$ patients had paraesthesia and $2 \%$ patients had a palpable superficial vein thrombus one week after the procedure.

Table 5: Occurrence of Complications in Patients after EVLT

\begin{tabular}{|c|c|c|c|c|}
\hline Complications & $\begin{array}{c}\text { After treatment 1 } \\
\text { week }\end{array}$ & $\begin{array}{c}\text { After treatment } \\
\text { 1 Month }\end{array}$ & $\begin{array}{c}\text { After treatment } \\
\text { 3 Months }\end{array}$ & $\begin{array}{c}\text { After treatment } 6 \\
\text { Month }\end{array}$ \\
\hline Pain & $31[62.0 \%]$ & 0 & 0 & 0 \\
\hline Paraesthesia & $05[10.0 \%]$ & 0 & 0 & 0 \\
\hline Superficial Thrombus & $01[2.00 \%]$ & 0 & 0 & 0 \\
\hline
\end{tabular}

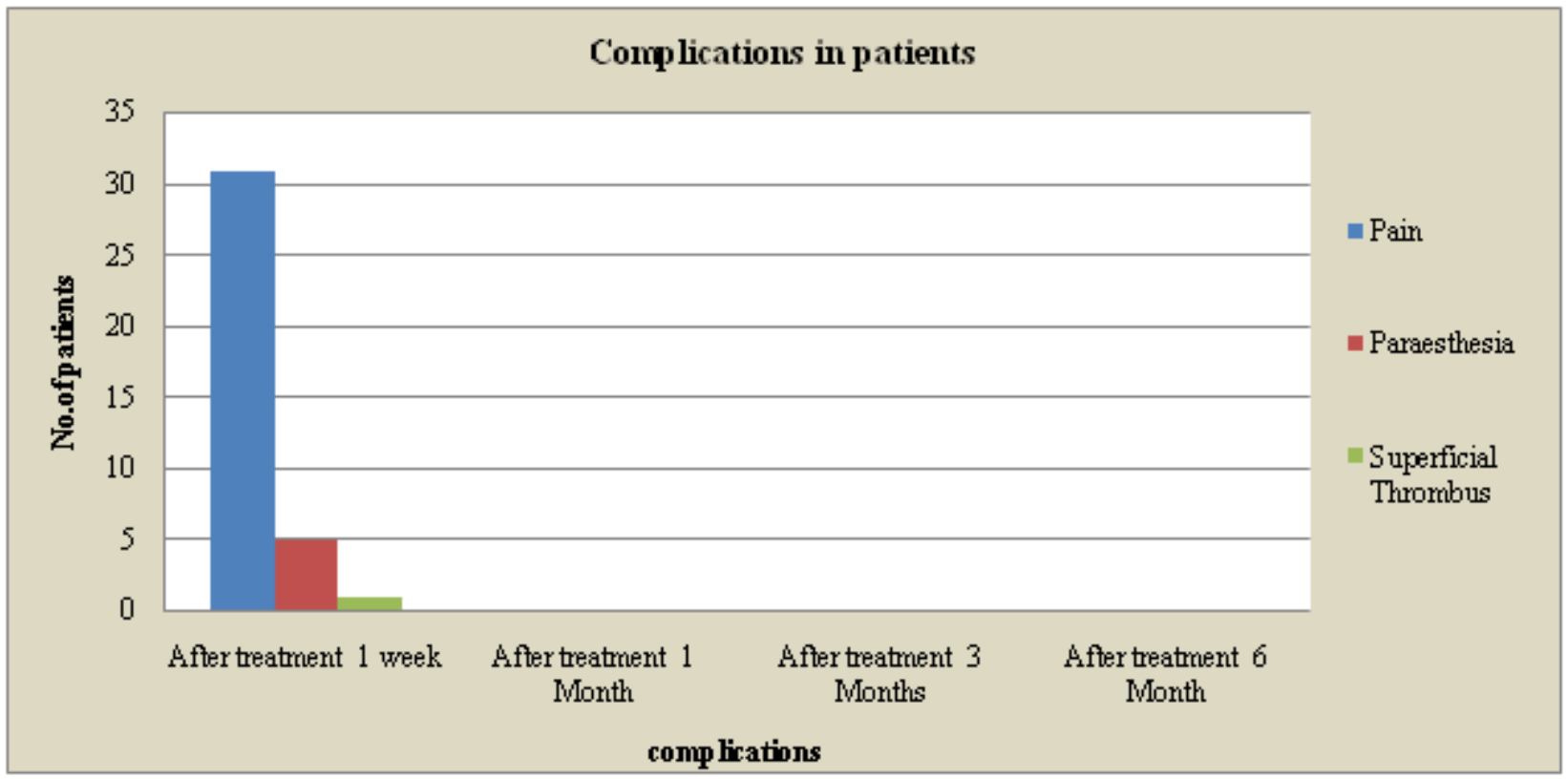

Graph 4: Occurrence of Complications in Patients after EVLT 


\section{International Journal of Science and Research (IJSR) \\ ISSN (Online): 2319-7064 \\ Index Copernicus Value (2013): 6.14 | Impact Factor (2014): 5.611}

\section{Discussion}

The high incidence of varicose veins in our population coupled with the advent of newer minimally invasive procedures being introduced in recent times has made it necessary to study in detail their advantages and disadvantages to find a quick, easy, minimally invasive, effective treatment for our patients.

The follow-up results of EVLT are therefore important to guide surgeons and patients in choosing of treatment modalities.

Two out of 50 patients were known cases of DVT who were treated with Warfarin previously. Their Doppler was suggestive of good flow with partial to near total recanalisation after which decision of EVLT in the same limb was taken. Similarly there were 6 patients with GSV thrombosis who were treated with Aspirin before hand and recanalisation/good flow confirmed on Doppler. Thus although superficial and deep vein thrombosis are contraindications to endovenous laser therapy, after appropriate management and confirming patency of lumen on ultrasound even these patients can be taken up for endovenous laser therapy.

During this study the Mean value of the length ablated was $52.3 \pm 18.63 \mathrm{~cm}$, Mean value of time taken was $230 \pm 82.86$ seconds, Mean value of the energy used was 5147.96 \pm 1780.95 Joules and Mean value of Power being $31.68 \pm 14.84$ Watts, using a $980 \mathrm{~nm}$ diode laser. In the study by Celalettin et $\mathrm{al}^{2}$ energy used was 2783.3 \pm 426.1 Joule,mean length ablated was $31.1 \pm 3.3 \mathrm{~cm}$, with a $980 \mathrm{~nm}$ Diode laser. The energy,power used time taken depend on the total length of the vein/s ablated amongother parameters, the results of the present study are thus compatible with other studies.

26\% of our patients required Foam Sclerotherapy for the treatment of residual varicosities, immediately after Endovenous Laser therapy in the same sitting. Thus any residual varicosities were tackled immediately. Even amongst the patients who did not undergo FST, there was no evidence of residual varices on follow-up. None of our patients returned with newly formed varices over areas that were not treated. In the study by Chih Yang et $\mathrm{al}^{3} 40.7 \%$ of the patients and $17.6 \%$ of the patients required Foam Sclerotherapy for residual varicosities following EVLT and CHIVA procedures respectively.

Residual varicosities were seen in $16.7 \%$ patients of EVLT and in $31.2 \%$ patients of cryostripping in the study conducted by Kwang et $\mathrm{al}^{4}$. There were $5 \%$ patients of residual varicosities following RFA in the study by Ahmed et $\mathrm{al}^{5}$ and $0.9 \%$ in the patients of EVLT in the study by K.A.Myers ${ }^{6}$. Our present study thus shows results similar to other studies, that EVLT results in fewer residual varicosities as compared to surgery.

$62 \%$ of the patients had normal Body Mass Index, 26\% patients were overweight and $12 \%$ were obese. Out of the 2 patients who returned with recurrence, one had normal BMI and the other was overweight.BMI does not appear to influence incidence, occlusion or recurrence rates. In the study by N.S. Theivakumar et $\mathrm{al}^{7}$ they deduced that BMI does not influence occlusion rates.

Most of the patients (58\%) complained of mild pain 1 week after the procedure, $34 \%$ had no pain while $4 \%$ had moderate pain. According to a study by Samuel et $\mathrm{al}^{\mathbf{8}}$ post operative pain is low after EVLT $(\mathrm{P}>0.05)$. In the study by Fernando et $\mathrm{al}^{9}$ median pain score is 3 after 1 month of the procedure. During the study by Kwang et $\mathrm{al}^{4} 8.3 \%$ of the patients had post operative pain after EVLT and $12.5 \%$ of the patients had post operative pain after cryostripping at a median follow up of 29.6 months. In the study by Ahmed et $\mathrm{al}^{5} 2 \%$ of the patients had postoperative pain 1 month after Radiofrequency ablation. None of our patients had pain on the 1st ,3rd or 6th month after the procedure thus our results are compatible with results of other studies and comparable to other methods also which were evaluated in other studies.

The symptoms of dilated veins and oedema have significantly reduced within 1 week $(\mathrm{p}<0.000)$. Dilated veins disappeared immediately after the procedure as evidenced by pre and immediate post operative photos taken in the operation theatre (Photos-2\&3). Also itching significantly reduced after one month ( $>00.05)$ and ulcers after 3 months $(p<0.000)$. According to the study by Celalettin et al there was significant reduction in itching and ankle swelling within 1 week of EVLT $\left(\mathrm{p}^{<0.000)}\right.$.

According to the statistical analysis, reduction in pigmentation $(p=0.327)$, eczema $(p=0.153)$ and bleeding $(p=0.315)$ is not significant. However, eczema that was present in only 2 patients disappeared after 1 month, bleeding that was present in 1 patient disappeared immediately. Pigmentation was still present in 5 out of 8 patients at 6 months but it had significantly faded over time.

In our study, $16 \%$ patients had ecchymosis, $10 \%$ patients had paraesthesia and $2 \%$ patients had a palpable superficial vein thrombus one week after the procedure which disappeared before the 2nd follow-up visit (before 1 month). None of our patients had haematoma formation, infection, DVT as complications.

According to the study by Tan KK et al ${ }^{10} 2 \%$ of the patients had ecchymosis and $10.7 \%$ of the patients had paraesthesia. In the study by Lars et $\mathrm{al}^{11}$ in the patients who underwent EVLT 11\% patients had ecchymosis,5\% had haematoma and $3 \%$ had superficial vein thrombosis while the patients undergoing High ligation and stripping 2\% patients had haematoma, $2 \%$ had paraesthesia and $3 \%$ had superficial vein thrombosis over a span of 1 month.

According to the study by RR Vanderbos et $\mathrm{al}^{12}$ in the patients who underwent EVLT 13.1\% patients had ecchymosis, 9.2\% patients had superficial thrombus and 0.9\% patients had DVT while amongst the patients who underwent Endovenous Steam Ablation3.1\% patients had eccymosis, 8.5\% patients had superficial thrombus and $0.9 \%$ had nerve injury.

In the study by Celalettin et $\mathrm{al}^{2} 2.5 \%$ of the patients had haematomas, 5.5\% patients had paraesthesias and $4 \%$ had superficial vein thrombosis. $1 \%$ patients showed signs of 


\section{International Journal of Science and Research (IJSR) \\ ISSN (Online): 2319-7064 \\ Index Copernicus Value (2013): 6.14 | Impact Factor (2014): 5.611}

infection. During the study by Knuth Ras et al $^{13}$ amongst the patients who underwent EVLT 9\% had paraesthesia,1\% had infection, $0.6 \%$ had DVT and 91\% had ecchymosis whereas amongst the patients of high ligation and stripping $14 \%$ had paraesthesia,0.6\% had DVT and 90\% had ecchymosis. According to the study by Kwang et $\mathrm{al}^{4}$ amongst the patients who underwent EVLT $16.7 \%$ had ecchymosis, 8.3 had paraesthesia while amongst the patients of Cryostripping $31.2 \%$ patient had ecchymosis, 12.5 had paraesthesia.

According to the study by Nedzad et $\mathrm{al}^{14} 8.1 \%$ of the patients of VLT developed haematomas on the 7th day while amongst the patients of high ligation and stripping $48.2 \%$ patients had haematomas, 5.1\% had infection and 3.4\% had DVT .

Our study shows disappearance of most of the symptoms and signs of varicose veins after EVLT. Dilated veins and bleeding disappeared immediately after the procedure while oedema, eczema, itching, ulcers disappeared with time. Some patients had pigmentation present even after 6 months but the intensity had greatly faded. Thus, our study showed marked regression of symptoms post EVLT and showed similar results to other studies on the outcomes of EVLT and the outcomes of other minimally invasive procedures like RFA. Our study also suggested superior outcomes of EVLT as compared to conventional surgery (high ligation and stripping) as shown by the results of other studies.

Rate of recurrence post EVLT was $2.4 \%$ in the study by Tan $\mathrm{KK}$ et $\mathrm{al}^{\mathbf{1 0}}, 7 \%$ in the study by Celalettin et $\mathrm{al}^{2}, 5.6 \%$ in the study by Kwang et $\mathrm{al}^{4}$ and $4 \%$ in our study.There was recurrence in $9.4 \%$ patients of cryostripping according to the study by Kwang et $\mathrm{al}^{4}$ and $0.5 \%$ in patients of RFA in the study by Ahmed et al. ${ }^{5}$ Therefore, we can conclude that EVLT has recurrence rates, similar to other minimally invasive procedures and has lower recurrent rates as compared to conventional surgery.

\section{Summary}

Minimally invasive procedures for varicose veins are now being opted by surgeons and patients alike for the advantages like less pain and quicker recovery. This study was therefore taken up to evaluate the outcomes of endovenous laser therapy and compare them with the outcomes of other minimally invasive procedures so that we can make an informed decision regarding the best suited treatment modality for our patients.

In the present study 50 patients of varicose veins of the lower limbs were enrolled and after thorough history taking, general and local examination, venous colour Doppler and basic preoperative work up, were subjected to endovenous laser therapy under local anaesthesia under ultrasonography guidance. Foam sclerotherapy was given as an adjuvant treatment in the same sitting in case of any residual varicosities. Patients were followed up after 1 week, 1 month, 3 months and 6 months and regression of symptoms alongwith occurrence of any complications were noted to assess the overall outcome and efficacy of Endovenous Laser therapy.
Most of the of the patients of varicose vein to undergo Endovenous Laser therapy were female [68\% were female and $32 \%$ were male] .

We had patients of ages ranging from 21 to 74 years with most of the patients belonging to the $41-50$ years of age group.

$74 \%$ of the patients presented with unilateral signs and symptoms with $26 \%$ showing bilateral involvement. The more common side involved was left side (66\%) compared to right side (34\%).

The most common vein involved was the GSV (94\%) in our study. $82 \%$ had exclusive GSV involvement,6\%had exclusive SSV involvement with $12 \%$ having both veins involved.

In the present study $60 \%$ patients had perforator incompetence , $86 \%$ and $14 \%$ had SFJ and SPJ incompetence respectively. $4 \%$ patients were known case of DVT while $6 \%$ were known cases of superficial vein thrombosis.

The energy and power used; and the time taken depend on the total length of the vein/veins ablated, among other parameters.

26\% of our patients required Foam Sclerotherapy for the treatment of residual varicosities, immediately after Endovenous Laser therapy in the same sitting.

The average number of days the patients were kept admitted was 2 days. Hence our study shows that EVLT can be done as a day care procedure.

Most of our patients (62\%) had normal Body Mass Index, $26 \%$ patients were overweight and $12 \%$ were obese.

Most of the patients (58\%) complained of mild pain 1 week after the procedure, $34 \%$ had no pain while $4 \%$ had moderate pain

Dilated veins and bleeding disappeared immediately after EVLT. While edema, eczema, ulcers and itching disappeared with time. Pigmentation was still present in some patients at 6 months, but its intensity had significantly faded with time.

$62 \%$ of the patients complained of pain , $16 \%$ patients had ecchymosis, $10 \%$ patients had paraesthesia and $2 \%$ patients had a palpable superficial vein thrombus one week after the procedure., which disappeared before the $2^{\text {nd }}$ follow-up visit (before 1 month). Only 4\% of our patients returned with recurrence.

\section{Conclusion}

In conclusion we think that EVLT is an efficient treatment modality as proved by the study of its outcomes and comparing them with world literature. It is safe, effective, quick, leading to faster recovery and return to daily activities. There is evidence of early disappearance of signs and symptoms, low complication and low recurrence rate. 


\section{International Journal of Science and Research (IJSR) \\ ISSN (Online): 2319-7064 \\ Index Copernicus Value (2013): 6.14 | Impact Factor (2014): 5.611}

The advantages greatly outweigh the disadvantages and it is highly recommended as an effective day care surgical procedure for the treatment of varicose veins.

\section{References}

[1] Callam MJ.Epidemiology of varicose veins. Br J Surg 1994; 81:167-73.

[2] Celalettin Karatepe, Mustafa Aldemir and Onur Goksel. Endovenous Laser Therapy of Great Saphenous Vein: Six Months Follow-UpKaratepe and Goksel, Anat Physiol 2014, 4:4. http://dx.doi.org/ 10.4172/21610940.1000152

[3] ChihYang Chan, TzuChun Chen, YungKun Hsieh, JihHsin Huang. Retrospective Comparison of Clinical Outcomes between Endovenous Laser and Saphenous Veinsparing Surgery for Treatment of Varicose Veins. World Journal of Surgery July 2011, Volume 35, Issue 7, pp 16791686 First online: 21 April 2011.

[4] Kwang Hyoung Lee, M.D., Jae Ho Chung, M.D., Kwang Taik Kim, M.D., Ph.D., Sung Ho Lee, M.D., Ph.D., Ho Sung Son, M.D., Ph.D., Jae Seung Jung, M.D., Ph.D., Hee Jung Kim, M.D., Seung Hun Lee, M.D. Comparative Study of Cryostripping and Endovenous Laser Therapy for Varicose Veins: MidTerm Results. Korean J Thorac Cardiovasc Surg 2015; $48: 345-350$.

[5] Ahmed Kayssi, MD, MSc, MPH Marc Pope MD, MSc Ivica Vucemilo, MD Christiane Werneck, MD, $\mathrm{MScCH}$. Endovenous radiofrequency ablation for the treatment of varicose veins. Can J Surg, Vol. 58, No. 2, April 2015.

[6] K.A. Myersa, D.Jolleyb. Outcome of Endovenous Laser Therapy for Saphenous Reflux and Varicose Veins : MediumTerm Results Assessed by Ultrasound Surveillance. European Journal of Vascular and Endovascular Surgery Volume 37, Issue 2, February 2009, Pages 239-245.

[7] N.S. Theivacumar, D. Dellagrammaticas, R.J. Beale, A.I.D. Mavor, M.J. Gough. Factors Influencing the Effectiveness of Endovenous Laser Ablation (EVLA) in the Treatment of Great Saphenous Vein Reflux. Leeds Vascular Institute, The General Infirmary at Leeds, UK. European J of Vascular \& Endovascular Surgery.January 2008; Volume 35, Issue 1, Pages 119123.

[8] Samuel N, Carradice D, Wallace T, Mekako A, Hatfield J, Chetter I. Randomized clinical trial of endovenous laser ablation versus conventional surgery for small saphenous varicose veins. Nehemiah.samuel@hey.nhs.uk Ann Surg. 2013 Mar;257(3):419-26. 10.1097/SLA.0b013e318275f4e4.

[9] Fernando RS, Muthu C. Adoption of endovenous laser treatment as the primary treatment modality for varicose veins : The Auckland City Hospital Experience. N Z Med J. 2014 Aug 1;127(1399):43-50.

[10] Tan K.K, Nalachandran S, Chia K. Endovenous laser treatment for varicose veins in Singapore: a single centre experience of 169 patients over two years. Singapore Med J 2009; 50(6): 591-594.

[11] Lars H. Rasmussen, MD, DMSC, Lars Bjoern, MD, Martin Lawaetz, BS, Allan Blemings, MSc, Birgit
Lawaetz, RN, and Bo Eklof, MD, PhD, Naestved and Roskilde, Denmark. Randomized trial comparing endovenous laser ablation of the great saphenous vein with high ligation and stripping in patients with varicose veins: Short-term results. J Vasc Surg 2007;46:308-15.

[12] R.R.van den Bos, W.S.J. Malskat, M.G.R. De Maeseneer, K.P.de Roos, D.A.G.Groeneweg, M.A.Kockaert, .A.M.Neumann and T.Nijsten. Randomized clinical trial of endovenous laser ablation versus steam ablation (Last trial) for great saphenous varicose veins. BJS Society Ltd BJS Published by JohnWiley \& Sons Ltd. 2014.

[13] Knuth Rass, MD; Norbert Frings, MD; Paul Glowacki; Corinna Hamsch, MD; Stefan Gr äber, MD; Thomas Vogt, MD; Wolfgang Tilgen, MD. Comparable Effectiveness of Endovenous Laser Ablation and High Ligation With Stripping of the Great Saphenous Vein Two Year Results of a Randomized Clinical Trial (RELACS Study). Arch Dermatol. 2012;148(1): 4958. doi: 10.1001/archdermatol.2011.272.

[14] Nedzad Rustempasic, Alemko Cvorak, Alija Agincic. Outcome of Endovenous Laser Ablation of Varicose Veins. Acta Inform Med. 2014 Dec 22(6) : 329-332.

\section{Author Profile}

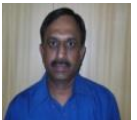

Bhaskar Musande is Professor, Department of Surgery, MGM Medical College \&Hospital, Aurangabad.

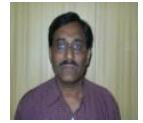

Manohar Kalbande is Professor, Department of Cardio-Vascular \&Thoracic Surgery, MGMMedical College \& Hospital, Aurangabad.

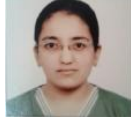

Tanvi Tolat is Junior Resident, Department of Surgery, MGM Medical College \&Hospital, Aurangabad. 